to improve standards, to decrease uncritical speculation, and to encourage the strict and informed refereeing of research papers expected of an academic journal. Without tighter editorial grip, Robotica will be unable to attract important new material.

William Clocksin is a GEC Fellow in Robotics at St Cross College, Oxford.

\section{Bench power}

\section{A.N. Barrett}

\section{Laboratory Microcomputer.}

Editor Brian Millard.

Science and Technology Letters, 12 Clarence Rd, Kew, Surrey, UK. 4/yr. f10, $\$ 18$.

THE intended aim of this low cost journal is that it should become the community forum of all who work in the physical, life and medical sciences and who are serious users of microcomputers.

The majority of the papers however, are submitted from chemical laboratories and unless more contributions from other disciplines are found the journal will have failed to achieve its aim. A further limitation may also result from the editorial intention to publish papers which require the reader "to exert more than average concentration thereby giving the reader a great feeling of satisfaction when the penny drops". This will undoubtedly discourage many scientists from other disciplines submitting papers since they may be rejected as being unsophisticated.

Despite these criticisms, there are some interesting and useful papers dealing with microcomputing in the chemical laboratory which cover general problems of interfacing, data acquisition and analysis. However, one particular paper was surprising, in that it made no reference to microcomputers and occupied over one quarter of the contents of a single issue. Several references to the CRAY-1 were made however and, despite exerting much more than average concentration, I failed to equate a machine of this capacity with a laboratory microcomputer.

Two potentially useful features of the journal are a letters page and a section dealing with general marketing developments of packages and hardware components. Each issue contains around 30 pages and publishes an average of four papers approximately six pages long. The editorial section however appears to have vanished from the last two issues and there are no book reviews. Considering the cost, the quality of print is reasonable although there are many typographical errors.

\section{Plate \\ pursuits}

\section{Ian W.D. Dalziel}

Tectonics.

Editor-in-chief John F. Dewey.

American Geophysical Union/European

Geophysical Society. 6/yr. \$22.

IT HAS often been pointed out that one of the most compelling aspects of the theory of plate tectonics is that it helps to explain many otherwise seemingly unrelated facts from a broad spectrum of disciplines covering the earth sciences. Therefore, it is hardly surprising that it should have directly sparked the new journal, Tectonics.

The editorial policy for the journal as set out by the international group of Editors in Volume 1 No.1 states that "The central theme of Tectonics is the mechanical and thermal evolution of the lithospheric crust and mantle and the way that this is reflected in cratons, basins and mountains from the broad regional scale to the fine scale." Certainly the range of topics covered by the articles published to date falls within this area although the coverage is, understandably, rather patchy.

Precambrian to contemporary tectonics throughout the world has been considered but the bias has been towards America. The editorial policy aims for a "very rapid reviewing process, allowing a maximum of about one month between submission and notification to the author of acceptance or

\section{Mineral spread}

\section{R.D. Adams}

Geophysical Journal (cover-to-cover translation of Geofizicheskii Zhurnal).

Editor-in-chief A.V. Chekunov.

Gordon \& Breach. 6/yr. £250, \$375.

IT IS not obvious from its title that this is, in fact, a journal of the Ukranian Academy of Sciences. It was first published in 1979, and the American translation runs from Volume 3 (1981).

The journal is mainly related to the solid earth, concentrating on seismology, gravity, geomagnetism and heat flow, but there are also contributions in fluid geophysics. As with many local journals, papers include some giving rather full treatment of restricted subjects, but there are also general reviews of wider interest and a few rather provocative 'discussion' papers. Prominent among these is one on the practical use of scientific (and especially geophysical) discovery to industry, illustrated with numerous quotations from Marx, and alluding to the advantage that western scientists have in the avail- rejection." While it is not possible to deduce from the journal precisely how close the editors are to approaching this goal, publication has been amazingly rapid, many articles have been accepted within one month (several on the day of receipt!), and almost all have been published within three months of the acceptance date. It should be borne in mind that camera-ready copy is prepared by the authors. This detracts from appearance, but does speed publication and keep costs down. With six issues per year and an average of 4.5 articles per issue to date, the journal seems on paper to be good value. A change to a larger $(81 / 2 \times 11$ inches $)$ format for volume 2 was an improvement.

However, it is not yet quite clear what niche the journal will occupy in the long term. One worry is that it will become the vehicle for too many speculative papers with titles such as "A Plate Tectonic Model of the Such and Such Range", and carry too few papers of lasting value. Nonetheless, despite having co-authored the first article to be published in the fledgling journal, this reviewer believes that Tectonics is starting to attract more of the latter type, and that with a combination of editorial vigour in soliciting interesting articles, coupled with good judgement in the selection of reviewers and quality control, it has the potential to become an important part of the publication scene in the earth sciences.

Ian W.D. Dalziel is Professor of Geology in the Department of Geological Sciences at the Lamont-Doherty Geological Observatory, Columbia University.

ability of cover-to-cover translations of Soviet journals, whereas Soviet scientists have no reciprocal benefit.

The production is of high quality, with illustrations and technical printing at least as good as in the Russian version; the translation is excellent and a great improvement on the English contents and summaries in the original journal.

The cost for each six-part yearly volume

\section{GEOPHXSCAL OURNAL}

is very high compared with the Russian original and the journal is not likely to attract personal subscribers. Many papers will interest specialists, however, particularly those interested in details of Soviet geophysical methods, but this is not a journal in which Soviet geophysicists are likely to place their main contributions. It is a sound, competent journal, and for the sake of completeness it merits a place in the libraries of major geophysical institutions.

R.D. Adams is at the International Seismo logical Centre, Newbury, and Department of Geology, University of Reading. 